\title{
Avaliação do Programa Bolsa Família na segurança alimentar das famílias rurais do município de Rio Verde, GO: efeitos, entraves e diferenciações
}

Evaluation of Bolsa Familia Program in the alimentary safety of rural families in the municipality of Rio Verde, GO: effects, obstacles and differentiation

\section{Évaluation du Programme Bolsa Familia sur la sécurité alimentaire des familles rurales de la ville de Rio Verde, GO: effets, empêchement et différenciations}

\section{Evaluación del Programa Bolsa Familia em la seguridad alimentaria de las familias rurales del municipio de Rio Verde, GO: efectos, impedimentos y diferencias}

\author{
Frankcione Borges de Almeida* \\ (frankcione.almeida@ifgoiano.edu.br) \\ Luiz Manoel de Moraes Camargo Almeida** \\ (manoel77@yahoo.com.br) \\ Vera Lúcia Silveira Botta Ferrante*** \\ (mestrado@uniara.com.br/vbotta@techs.com.br)
}

Recebido em 20/03/2015; revisado e aprovado em 24/07/2015; aceito em 31/07/2015

DOI: http:/ /dx.doi.org/10.1590/151870122015204

\begin{abstract}
Resumo: O objetivo deste estudo foi demonstrar os efeitos, entraves e diferenciações do Programa Bolsa Família (PBF) na Segurança Alimentar das famílias rurais do município de Rio Verde, GO. Os resultados avançaram na avaliação da eficácia e na identificação dos entraves da Gestão Municipal nos eixos de atuação do PBF e revelaram que o universo empírico estudado não completa o ciclo da política com o estágio de avaliação.

Palavras-chave: Políticas públicas. Programa Bolsa Família. Segurança alimentar e nutricional.
\end{abstract}

\begin{abstract}
This study had the objective of showing the effects, obstacles and differentiation of Family Bag Program (FBP) in the Alimentary Safety of rural families in the municipality of Rio Verde, GO. The results advanced in the evaluation of the efficacy and the identification of obstacles of the Municipal Management in the acting axis of FBP and reveal that, in the researched empirical universe, the cycle of this program is not completed with the evaluation stage.
\end{abstract}

Key words: Public policies. Family Bag Program. Nutritional and alimentary safety.

Résumé: Le but de cette étude était de démontrer les efftes, empêchement et differentes variabilités de Programme Bolsa Familia (PBF) sur la sécurité alimentaire des familles rurales de la commune de Rio Verde, GO. Les résultats étaient insuffisants, selon l'estimation et la prévue de la gestion de commune au niveau de la situation de programme bourse familial et a révélé que l'univers empirique étudié pas terminé le cycle que l'univers empirique étudié pas compléte le cycle de la politique exijé dans l'estimation.

Mots-clés: Politique publique. Programme Bourse Familial. Securite alimnentaire et nutritionnelle.

Resúmen: Este estúdio tuvo como objetivo demonstrar los efectos, impedimentos y diferencias del Programa Bolsa Família (PBF) en la Seguridad alimentaria de las familias del municipio de Rio Verde (GO). Los resultados ayudaron em la evaluación de la eficacia y em la identificación de los obstáculos por parte de la Gestión Municipal em los ejes de actuación del PBF, y evelaron que el universo experimental estudiado no completa el período de evaluación. Palabras clave: Políticas públicas. Programa Bolsa Família. Seguridad alimentaria y nutricional.

\section{Introdução}

Segundo Menezes (1998), o Brasil segue uma tendência mundial em que se identificam índices de pobreza e carência nutricional mais altos no meio rural do que no urbano, mesmo com os avanços obtidos nos últimos anos na gestão do governo federal em termos de formulação de política pública, mudanças na legislação, ampliação do crédito produtivo e aumento da produção.

Na Pesquisa Nacional por Amostra de Domicílios (PNAD) de 2009, cujos resultados foram divulgados pelo Instituto Brasileiro

\footnotetext{
* Instituto Federal de Educação, Ciência e Tecnologia Goiano (IF Goiano), Campus Rio Verde, Goiás, Brasil.

** Centro em Ciências da Natureza do Campus Lagoa do Sino da Universidade Federal de São Carlos (UFSCAR), Buri, São Paulo, Brasil.

*** Centro Universitário de Araraquara (UNIARA), Araraquara, São Paulo, Brasil.
} 
de Geografia e Estatística (IBGE) (BRASIL, 2010a), a prevalência de Insegurança Alimentar (IA) moderada ${ }^{1}$ ou grave ${ }^{2}$ foi maior nos domicílios das áreas rurais do que nos das áreas urbanas.

Em relação a 2004, houve uma queda na proporção de domicílios em situação de IA grave e moderada, tanto na área urbana quanto na rural. Entre 2004 e 2009, a redução da proporção de domicílios com moradores em situação de IA caiu na área urbana (de $33,3 \%$ para $29,4 \%$ ) e na rural (de $43,6 \%$ para $35,1 \%)$, contudo, ao desagregar por intensidade de IA, verificou-se que, na área rural, ocorreu redução da prevalência de domicílios em IA leve ${ }^{3}$, o que não foi encontrado na área urbana.

Um dos maiores desafios do governo é conciliar o crescimento econômico com a erradicação da pobreza, principalmente no meio rural, pela necessidade de diminuir a desigualdade social e setorial. Nesse sentido, o Programa Bolsa Família surgiu como uma alternativa com o objetivo de combater a fome e promover a segurança alimentar e nutricional (SAN). É um programa de transferência direta de renda que beneficia famílias em situação de pobreza e de extrema pobreza em todo o Brasil. Integra o Plano Brasil Sem Miséria (BSM), que tem como foco de atuação milhões de brasileiros com renda familiar per capita inferior a $\mathrm{R} \$ 77,00$ mensais e está baseado na garantia de renda, na inclusão produtiva e no acesso aos serviços públicos (BRASIL, 2013).

Para a população, a discussão entre segurança alimentar e o combate à fome, o segundo prevalece no entendimento. Um dos fatores que contribuem para a dificuldade da compreensão é que o conceito de SAN ainda não foi assimilado no país, por ser um tema mais ligado às organizações não governamentais da área, embora a segurança alimentar e a

\footnotetext{
${ }^{1}$ Insegurança Alimentar Moderada: quando há restrições quantitativas especialmente relevantes entre pessoas adultas.

${ }^{2}$ Insegurança Alimentar Grave: quando há redução importante da quantidade de alimentos disponíveis, a adultos quanto às crianças.

${ }^{3}$ Insegurança Alimentar Leve: quando há preocupação ou incerteza quanto ao acesso aos alimentos, ou seja, risco para a sustentabilidade e comprometimento da qualidade da dieta.
}

fome sejam partes complementares (TAKAGI; BELIK, 2007).

A pobreza é um problema complexo, portanto não é fácil de ser resolvido. "Nos estudos sobre extrema pobreza, as realizações e capacidades centrais são básicas, relacionadas com nutrição, abrigo, em como evitar mortalidade prematura ou doenças" (KAGEYAMA, 2008, p. 55). A autora afirma ainda que essa abordagem advoga a ideia de pobreza como privação das necessidades básicas, e que a falta de renda pode ser a causa principal, mas não a única. A pobreza "real" pode ser muito maior do que aquela medida unicamente pela renda.

O problema não pode ser resolvido apenas por meio de um programa de transferência de renda como o PBF. Segundo o Instituto Brasileiro de Análises Sociais e Econômicas (IBASE) (BRASIL, 2008), na perspectiva de Amartya Sen, devem-se privilegiar as habilidades e as capacidades das pessoas e não apenas a renda e a posse de bens.

De acordo com Traldi (2011), com base na pesquisa do Instituto Brasileiro de Análises Sociais e Econômicas (IBASE) (BRASIL, 2008), a articulação de programas de SAN com o PBF fornece subsídios importantes para uma reflexão sobre a proposição de políticas públicas voltadas para a garantia do direito humano à alimentação adequada e emancipação das famílias brasileiras mais vulneráveis.

Em virtude dessa realidade, este estudo teve por objetivo demonstrar os efeitos, entraves e diferenciações do Programa Bolsa Família (PBF) na Segurança Alimentar das famílias rurais. Para avaliar o programa e atender os objetivos propostos, o desenvolvimento do trabalho teve apoio na análise quantitativa e qualitativa dos dados da pesquisa de campo realizada com aplicação de questionários no período de junho a outubro de 2013 com 94 famílias rurais beneficiárias do PBF, no município de Rio Verde, GO.

Esse município foi escolhido pela dicotomia apresentada no meio rural entre a riqueza propiciada pelo desenvolvimento do agronegócio e a pobreza de pequenos produtores e moradores de distritos marginalizados nesse modelo produtivista, os quais sobrevivem apenas do PBF e de outras redes de proteção e cooperação social. 


\section{Contornos teórico-metodológicos do trabalho}

Este artigo é baseado em revisão bibliográfica e na análise quantitativa e qualitativa dos dados provenientes de pesquisas de campo da dissertação de mestrado ${ }^{4}$ produzida pela primeira autora deste trabalho. $\mathrm{Na}$ pesquisa em questão, foi aplicado um questionário semiestruturado com as famílias rurais beneficiárias do PBF e foram realizadas entrevistas abertas com a gestão local do programa. Ambos os instrumentos utilizados na pesquisa foram adaptados de Traldi (2011) e de Santos (2011). Também foram utilizados dados estatísticos organizados e publicados por órgãos públicos.

As famílias entrevistadas residem em assentamentos rurais, distritos do município de Rio Verde e pequenas propriedades rurais. Para realizar a caracterização do perfil da situação socioeconômica e sociodemográfica dos sujeitos e de suas percepções em relação ao programa e às entidades responsáveis, foram analisadas as variáveis seguintes: renda, escolaridade, trabalho, perfil produtivo, autoconsumo e perfil alimentar e proteção social.

Para medir a situação da segurança alimentar e nutricional, foi utilizada a Escala Brasileira de Insegurança Alimentar (EBIA). A EBIA é aplicada diretamente a uma pessoa da família que seja responsável pela alimentação do domicílio, por meio de um questionário composto por 15 questões fechadas, o que possibilita estimar a prevalência de segurança alimentar e que classifica as famílias pesquisadas em quatro níveis ${ }^{5}$. Também para ampliar analiticamente as condições de segu-

\footnotetext{
${ }^{4}$ A pesquisa aqui relatada seguiu o protocolo de ética em pesquisa com seres humanos e foi aprovada pelo Comitê de Ética em Pesquisa (CEP) da Universidade Federal de Goiás (UFG) sob o número 047/2013.

${ }^{5}$ (1) Segurança alimentar (SA): quando não há restrição alimentar de qualquer natureza, nem mesmo a preocupação com a falta de alimentos no futuro; (2) Insegurança Alimentar Leve (IAL): quando há preocupação ou incerteza quanto ao acesso aos alimentos, ou seja, risco para a sustentabilidade e comprometimento da qualidade da dieta; (3) Insegurança Alimentar Moderada (IAM): quando há restrições quantitativas especialmente relevantes entre pessoas adultas e; (4) Insegurança Alimentar Grave (IAG): quando há redução importante da quantidade de alimentos disponíveis, tantos aos adultos quanto às crianças.
}

rança alimentar, foi realizado um cruzamento da EBIA com as variáveis: renda agrícola e não agrícola; nível de escolaridade do chefe de família e do beneficiário; pluriatividade ${ }^{6}$; nível de diversificação da produção; nível de autoconsumo e discriminação das famílias por realização das refeições diárias e auxílios recebidos.

Para avaliar a eficácia e demonstrar os entraves institucionais e organizacionais da gestão do PBF em Rio Verde, GO, foram feitas entrevistas com os gestores da saúde, educação e assistência social que integram a gestão local do Programa. Visou-se analisar a gestão local, infraestrutura, recursos humanos e financeiros, comunicação, cadastramento, condicionalidades, controle social, intersetorialidade, gestão compartilhada e segurança alimentar.

A eficácia corresponde ao resultado de um processo, entretanto contempla também a orientação metodológica adotada e a atuação estabelecida na consecução dos objetivos e metas, em um tempo determinado, tendo em vista o plano, programa ou projeto originalmente exposto.

Entraves são filtros institucionais e organizacionais que dificultam a capacidade de operação e de obtenção de recursos dos atores em uma política pública. Filtros institucionais (regras, normas, políticas públicas, convenções de mercado etc.) pesam sobre as atuações dos atores e, quando se consolidam, passam a filtrar as capacidades destes de produzir, negociar, obter recursos e permanecer nos mercados (avançando ou retrocedendo). O diagnóstico dos filtros institucionais é fundamental para o encaminhamento de políticas públicas e privadas de aprimoramento da competitividade (ALMEIDA, 2009).

\footnotetext{
${ }^{6}$ Pluriatividade: uma unidade de análise que tem como referência a propriedade produtiva multidimensional, em que empreendem atividades agrícolas e não agrícolas dentro e fora do estabelecimento, e pelas quais diferentes tipos de remuneração são recebidos. Incluemse atividades não necessariamente remuneradas em dinheiro, atividades assalariadas e por conta própria.
} 


\section{Revisão bibliográfica}

\subsection{Programa Bolsa Família e segurança alimentar no meio rural}

Os programas de transferência de renda começaram a ser desenvolvidos em vários países da Europa a partir dos anos de 1930. Os programas de transferência de renda surgiram como uma alternativa para combater a pobreza. Eles foram concebidos segundo a ideia de que o beneficiário tem a autonomia para definir como melhor utilizar o benefício por saber quais são suas necessidades mais urgentes (SANTANA, 2007).

No Brasil, a temática dos programas de transferência de renda ganha espaço e tem seu desenvolvimento a partir dos anos noventa. Desde então, a transferência de renda se caracteriza como uma transferência monetária direta a indivíduos ou a famílias. No caso brasileiro, e de várias experiências da América Latina, são programas focalizados em segmentos pobres da população que, em geral, têm sua prestação condicionada a determinadas exigências.

No final do segundo mandato de Fernando Henrique Cardoso (1999-2003), foram lançadas algumas políticas voltadas para a melhoria da renda e da qualidade de vida da população mais pobre, tais como: Programa de Erradicação do Trabalho Infantil (PETI), Agente Jovem, Sentinela, Bolsa-Escola, Bolsa-Alimentação, Cartão-Alimentação e Auxílio-Gás.

Em 2003, primeiro ano do governo de Luiz Inácio Lula da Silva, foi criado o Ministério do Desenvolvimento Social e Combate à Fome (MDS), que centralizou as ações dos programas sociais geridos pelo governo federal. O principal avanço foi a unificação dos programas já existentes de transferência de renda. O governo incorporou e integrou, em um único programa, as ações públicas nas áreas de assistência social, segurança alimentar e nutricional, saúde, educação infantil e transferência de renda, denominando-o Programa Bolsa Família.

O governo Dilma lançou, em 2011, o programa Brasil Sem Miséria, cujo principal público-alvo são milhões de brasileiros com renda familiar per capita inferior a $\mathrm{R} \$ 77,00$ mensais, visando sua inserção na cidadania.
O mesmo tem ações nacionais e regionais baseadas em três eixos: a) garantia de renda, b) inclusão produtiva e c) acesso a serviços públicos. Houve uma continuidade dessas políticas no governo em relação ao anterior, havendo apenas algumas alterações, como, por exemplo, de "Fome Zero" para "Brasil Sem Miséria", abrangência do número de pessoas a serem atingidas e ampliação de alguns programas.

As políticas de transferência de renda podem ter papel relevante na melhoria das condições sociais e de segurança alimentar das famílias rurais beneficiárias, especialmente entre aquelas em situação de extrema pobreza e fome.

Os fatores que condicionaram a fome no mundo são distintos entre os territórios e municípios. Nos continentes asiático e africano, de modo geral, a fome é o resultado da ausência de alimentos, embora existam países em que a fome resulta da desigualdade social em condições extremas que ocasiona a falta de renda, educação e informação mínimas, além de ausência de empregos dignos para grande parte da população. Entretanto o acesso à renda mínima individual também não é garantia per si da segurança alimentar de um povo, embora em curto prazo seja uma medida bem-vinda, em longo prazo a renda mínima poderá se tornar o norte de um programa exclusivamente assistencialista, viciando ainda mais um sistema de perfil concentrador, desigual e excludente do qual a redução ou a precariedade do emprego e a escassez de saúde, educação e informação são os principais resultados (ALMEIDA, 2009; PAULILLO, 2010).

A segurança alimentar vai além, portanto, do acesso à renda porque deve ser reconhecida como um recurso fundamental de inclusão social. Isso significa fazer com que as camadas sociais marginalizadas tenham acesso a recursos básicos da vida em sociedade (emprego, educação, saúde, informação, etc.), de modo que possam participar das decisões que afetam suas vidas. Este último aspecto é muito importante, pois, com o avanço da globalização e a fragmentação do Estado, as agendas de decisões relevantes (em setores produtivos ou não produtivos) estão cada vez mais distantes e fechadas para a grande parte dos empreendedores (agricultores, 
comerciantes, pequenos industriais etc.) e trabalhadores (rurais e urbanos). Em algumas redes de decisões estratégicas, certos interesses estão fechados até mesmo para os governantes (ALMEIDA, 2009; PAULILLO, 2010).

Desde 1997, fruto da conferência mundial realizada pela FAO/ONU em Roma, as políticas de segurança alimentar devem responder pela produção e distribuição, assim como pelo acesso e consumo de alimentos através de uma cadeia ligada a valores fundamentais da população e expressados por meios dos cinco eixos (saúde, higiene, meio ambiente, autenticidade e solidariedade), todos socialmente construídos e compartidos na sociedade, nos mercados e nas políticas públicas (PAULILLO; PESSANHA, 2002).

No Brasil, mesmo as regiões com produções agroindustriais relevantes não resolveram as questões de segurança alimentar. $\mathrm{O}$ universo empírico estudado se destaca como um dos maiores produtores de grãos do país e, no entanto, conforme relatório divulgado pelo MDS baseado nos dados do censo de 2010, $4 \%$ da população apresentava situação de extrema pobreza (BRASIL, 2014b).

Segundo Brasil (2010a), a insegurança alimentar das famílias do meio rural é maior do que as do meio urbano em nível nacional. Esses dados apontam para o que foi levantado por Paulillo e Alves (2009), que defendem a criação de políticas de segurança alimentar direcionadas. Nesse sentido, fortalecem-se também as ideias de que as famílias rurais possuem prioridades diferenciadas, que o gasto com o benefício nem sempre é destinado à alimentação devido à especificidade e peculiaridades do meio rural e que a efetividade dos programas de segurança alimentar, no caso o PBF, tem especificidades, o que não significa a defesa, neste trabalho, de uma dicotomia rural-urbano, superada na teoria e na realidade contemporânea.

Campello e Neri (2013) destacam que, ao longo desses dez anos, o PBF criou uma nova estrutura, aperfeiçoou mecanismos, adicionou benefícios e ampliou o alcance e o impacto distributivo das transferências. $\mathrm{O}$ programa se consolidou e assumiu centralidade na política social brasileira. Internacionalmente é referência em tecnologia de transferência de renda condicionada e está entre as ações mais efetivas de combate à pobreza.
Questionamentos e críticas ao modelo do PBF sempre ocorrerão. De tempos em tempos, mesmo sistemas de proteção social muito consolidados passam por questionamentos e reformas. Haverá aqueles que defenderão sua transformação em um benefício de caráter universal e aqueles que argumentarão por um benefício de caráter mais restritivo. Mesmo para os mais críticos, seria difícil imaginar o Brasil sem um instrumento que vocalizasse e explicitasse as necessidades da parcela mais vulnerável da população. Ou em uma situação na qual os mais pobres não tivessem acesso a uma renda modesta - tanto do ponto de vista da família beneficiária quanto, especialmente, da renda nacional -, de natureza complementar à renda do trabalho. $\mathrm{Ou}$, ainda, em situação na qual as crianças continuassem apresentando taxas de extrema pobreza duas vezes mais altas que a média nacional (PAIVA; FALCÃO; BARTHOLO, 2013).

No rural, o PBF tem um desafio ainda maior: a geração de condições estruturantes que permitam a inclusão das famílias na sociedade, garantindo uma educação no campo e qualificação através de cursos que possibilitariam o acesso ao mercado de trabalho. Isso poderia melhorar as condições de vida e minimizar o êxodo rural.

\section{Resultados e discussões}

\subsection{O Programa Bolsa Família em Rio Verde, GO}

O Programa Bolsa Família (PBF) foi implantado no município em 2004, sendo de responsabilidade da Secretaria Municipal de Assistência Social. O programa está relacionado também com as Secretarias Municipais da Saúde, de Educação, Esporte e Lazer e com o Conselho Municipal de Assistência Social.

Segundo o MDS (BRASIL, 2014a), e de acordo com o censo IBGE de 2010 (BRASIL, 2010b), o município de Rio Verde, GO, tinha, naquele ano, as estimativas que estão apresentadas no Quadro 1. 


\begin{tabular}{|l|r|}
\hline Estimativa de famílias de baixa renda - Perfil Cadastro Único & 13.909 \\
\hline Estimativa de famílias pobres - Perfil Bolsa Família & 8.028 \\
\hline
\end{tabular}

Quadro 1 - Estimativa de famílias de baixa renda e pobres

Fonte: Adaptado de Brasil (2014a).

Ao fazer o levantamento de dados no Cadastro Único da Secretaria de Assistência Social de Rio Verde, pôde-se constatar que o número de famílias inscritas é bastante superior ao da estimativa do IBGE em 2010. Em setembro de 2012, existiam 17.238 famílias cadastradas em diversos programas sociais existentes, no entanto, em dezembro de 2013, o total de famílias inscritas no Cadastro Único havia se elevado para 24.636 famílias.

Observa-se que há uma disparidade entre o número de famílias de baixa renda estimadas pelo IBGE em 2010 e as cadastradas no CadÚnico do município. A resposta dada pela Secretaria de Assistência Social em relação a essa disparidade é que existe um grande número de famílias que migram para o município, principalmente das regiões norte e nordeste à procura de melhores condições de vida. O acompanhamento dessas famílias pelos assistentes sociais é fundamental para um diagnóstico preciso da real necessidade de cobertura pelo PBF.

Em relação às condicionalidades, a família assume alguns compromissos: as crianças e jovens devem frequentar a escola, as crianças precisam ser vacinadas e ter acompanhamento nutricional, e as gestantes devem fazer o pré-natal. Segundo o relatório de informações sociais, divulgado pelo MDS (BRASIL, 2014a), os indicadores do município de Rio Verde eram os seguintes:

a. Na educação, $74,01 \%$ das crianças e jovens de seis a dezessete anos do Bolsa Família têm acompanhamento de frequência escolar. A média nacional é de $85,84 \%$. O município está abaixo da média, por isso é importante que as secretarias de assistência social e de educação se articulem para melhorar esse percentual, ou seja, para aumentar o número de famílias cujos filhos têm frequência escolar verificada.

b. Na saúde: o acompanhamento da saúde das famílias chega a $84,7 \%$. Na vigência de dezembro de 2012 , atingiu $73,44 \%$. A média nacional é de 73,12\%. Quanto aos Benefícios Variáveis Gestantes (BVG) e Nutrizes (BVN), em março de 2013, no município, 45 famílias recebiam o BVG e 95 recebiam o BVN. Já em janeiro de 2014, 65 famílias recebiam o BVG e 108 recebiam o BVN.

Os dados divulgados pela Secretaria de Assistência Social de Rio Verde e também pelo MDS são apresentados de forma geral, não demonstrando dados específicos do meio rural no município. A divulgação dos resultados do rural e do urbano desses órgãos daria maior subsídio ao pesquisador, permitiria um comparativo com os resultados encontrados na pesquisa e traria uma maior transparência e eficácia ao PBF.

Este trabalho partiu do princípio de que os diagnósticos dos filtros institucionais são fundamentais para o encaminhamento de políticas públicas e privadas e de aprimoramento de suas eficácias. Nesse sentido, identificou-se um conjunto de eficácias e de entraves na gestão municipal do programa do Bolsa Família em Rio Verde, GO.

A Secretaria Municipal de Assistência Social de Rio Verde dispõe de uma estrutura física adequada para atender ao número de famílias que são atendidas pelo programa. Recentemente, houve uma reforma no local, e todo mobiliário e equipamentos foram substituídos por novos. Com a reforma, foi implantado o sistema de senha eletrônica, o que tem proporcionado mais agilidade no atendimento das famílias.

Verificou-se um entrave organizacional de recursos humanos, pois o número de assistentes sociais é insuficiente para o acompanhamento em função do número de famílias cadastradas e beneficiárias do programa. Nas entrevistas realizadas com as famílias rurais, detectou-se que estas nunca foram visitadas pela equipe da gestão local da assistência social; o contato se dá apenas no momento do recadastramento. Quadro este revelador de faltas graves no plano da gestão do programa.

$\mathrm{Na}$ visita aos locais selecionados para o estudo, constatou-se um entrave informacional relevante. Identificaram-se muitas famílias em situação de vulnerabilidade social que poderiam estar participando do PBF ou até mesmo estarem cadastradas para possível 
enquadramento em programas sociais destinados a famílias de baixa renda. Questionouse a uma das famílias encontradas nessa situação por que não estavam cadastradas em programas sociais. A responsável pela unidade familiar disse que desconhecia os critérios e que nunca foram visitados pela assistência social, recebiam apenas o acompanhamento dos agentes de saúde.

Segundo a assistente social da Secretaria de Assistência Social de Rio Verde, as metas de credenciamento ainda não foram cumpridas, e a principal tarefa é identificar as famílias em situação de vulnerabilidade que ainda não foram cadastradas.

$\mathrm{Na}$ área da saúde, a entrevista foi realizada com uma nutricionista, que também coordena o PBF. Percebeu-se que a situação se inverte, uma vez que a entrevistada relata que uma das maiores dificuldades no acompanhamento das condicionalidades seriam entraves de infraestrutura e de recursos humanos. Outro filtro organizacional, segundo a entrevistada, é a busca ativa das famílias, o que deveria ser feito por agentes comunitários.

$\mathrm{Na}$ entrevista com as famílias rurais, percebeu-se que apenas a Secretaria de Saúde, através dos agentes de saúde, faz um acompanhamento contínuo das famílias. Nas regiões em que há cobertura, o agente de saúde é como se fosse o canal de comunicação entre as famílias e o Programa. Assim, as famílias têm os agentes como facilitadores e tecem elogios a todos pelo trabalho desempenhado. Os agentes residem no local ou em regiões próximas e suas condições de trabalho não são favoráveis. Existe falta de equipamentos e de transporte para realização das visitas. Em alguns assentamentos, a distância entre um domicílio e outro é grande, e muitos dos agentes realizam as visitas a pé, a cavalo ou em veículo próprio, contatando-se um entrave proveniente do isolamento territorial do meio rural do município.

$\mathrm{Na}$ área da educação, o acompanhamento se restringe apenas ao monitoramento da frequência escolar, que é realizado bimestralmente. Os dados são levantados pelas unidades escolares, que os enviam ao gestor para conferência e posterior encaminhamento, via on-line, ao MDS. O gestor da educação não informou como é feito o acompanhamento das famílias que estão em descumprimento com a condicionalidade frequência escolar, identi- ficando um gravíssimo entrave institucional. Segundo ele, as principais dificuldades dos beneficiários são: evasão escolar, mudança de endereço (escola/cidade/estado) e falta de compromisso dos responsáveis pelas crianças.

Quando perguntados sobre: como está a situação de segurança alimentar no seu município? O que já está sendo feito e o que deveria ser feito para garantir a segurança alimentar dos beneficiários do Bolsa Família no seu município? Que políticas você identifica nesta área na secretaria da qual você faz parte? Os gestores deram a seguinte resposta: "não sei responder". Evidências de que os programas e políticas públicas têm que ser analisados em ação, não pelo discurso e/ou retórica da sua formulação.

Isso relata o desconhecimento por parte dos gestores que o programa tem sobre o recorte da temática segurança alimentar, refletindo-se em filtros informacionais e de transferência de conhecimento entre os atores do programa. Em trabalhos futuros, podem-se identificar que esses entraves tornam fracas as conexões da rede formada a partir dessa relevante política pública.

Em relação à Instância de Controle Social, esta é representada pelo Conselho de Assistência Social, não sendo exclusiva para o PBF. Segundo a assistente social, existem dificuldades em se tratar de assuntos específicos do PBF, já que o conselho precisa discutir problemas diversos relacionados à assistência social, e o tempo dispendido ao programa é inferior ao necessário. Torna-se o conselho apenas deliberativo o que é incipiente para a discussão e proposta de aprimoramento do programa.

No decorrer da pesquisa em questão, estava sendo implantado o Centro de Referência de Assistência Social (CRAS) nos distritos com o apoio das subprefeituras. Acredita-se que essa iniciativa vá melhorar o atendimento e acompanhamento das famílias que residem nesses locais e daquelas que residem em assentamentos próximos. Com a implantação do CRAS, poderão ocorrer também melhorias na oferta de cursos para capacitação profissional.

Detectou-se pouca articulação e comunicação entre as Secretarias que compõem o programa no município, e não foi possível durante a pesquisa identificar nenhuma ação sendo realizada em conjunto pelas Secretarias envolvidas no rural. 


\begin{tabular}{|c|c|}
\hline \multicolumn{2}{|r|}{ Principais efetividades e entraves identificados } \\
\hline Eficácias & $\begin{array}{l}\text { - Esforço e comprometimento quanto às metas de cadastramento e recadastramento; } \\
\text { - Satisfação dos beneficiários em relação ao atendimento no Cadastro Único; } \\
\text { - Implantação do CRAS nos distritos; } \\
\text { - Satisfação dos beneficiários quanto ao acompanhamento e atendimento pelos } \\
\text { agentes de saúde; } \\
\text { - Planejamento de ações que serão desenvolvidas em conjunto pelas secretarias en- } \\
\text { volvidas. }\end{array}$ \\
\hline $\begin{array}{c}\text { Entraves } \\
\text { institucionais e } \\
\text { organizacionais }\end{array}$ & $\begin{array}{l}\text { - Falta de investimento em infraestrutura e em funcionários diante da grande de- } \\
\text { manda; } \\
\text { - Espaço físico e quantidade de equipamentos inadequados para a Secretaria da } \\
\text { Saúde; } \\
\text { - Falta de comunicação entre gestão local e os beneficiários, em relação ao conheci- } \\
\text { mento do programa (100\% das famílias desconhecem o Eixo de Programas Com- } \\
\text { plementares); } \\
\text { - Ausência de cursos de capacitação para os beneficiários; } \\
\text { - Falta de atuação da instância de controle social, bem como a criação de conselho } \\
\text { específico e a inclusão de beneficiários no Conselho; } \\
\text { - Ausência do Conselho de Segurança Alimentar; } \\
\text { - Baixa intersetorialidade entre as entidades responsáveis pelas condicionalidades e } \\
\text { pelo controle social; } \\
\text { - Ausência de monitoramento e avaliação para aprimoramento do programa. }\end{array}$ \\
\hline
\end{tabular}

Quadro 2 - Diagnóstico e identificação das principais efetividades e entraves da gestão do PBF em Rio Verde, GO

Fonte: Elaboração própria (2013).

O Quadro 2 acima apresenta um resumo as principais efetividades e entraves identificados na análise qualitativa da gestão local. Observa-se, assim, que o PBF no município apresenta dificuldades de gestão que interferem diretamente no atendimento das famílias beneficiárias do programa.

A seguir, será apresentada a caracterização dos sujeitos desta pesquisa quanto a aspectos socioeconômicos e sociodemográficos.

4.2 Diagnóstico da situação socioeconômica e sociodemográfica das famílias rurais beneficiárias do Programa Bolsa Família em Rio Verde, GO

Para se delinear esse diagnóstico, foi necessária a avaliação de alguns quesitos.

\subsubsection{Caracterização das famílias: uma análise a partir das diferenciações entre moradores dos distritos rurais e pequenos produtores}

Das 375 famílias beneficiárias do PBF residentes no rural, 153 estão localizadas em pequenas propriedades e assentamentos rurais e 222 nos distritos. Foram entrevistadas 40 famílias das beneficiárias residentes em pequenas propriedades rurais e assentamentos, o que representa $26,14 \%$ do total das famílias entrevistadas. Nos distritos, foram entrevistadas 54 famílias, representando $57,45 \%$ do total das famílias entrevistadas.

Na maioria dos domicílios, os chefes de família possuem baixo grau de escolaridade. Tanto nos distritos quanto nos assentamentos rurais e pequenas propriedades, a faixa maior, entre os entrevistados, concentra-se no Ensino Fundamental I.

Apenas 20\% das famílias residentes nos distritos possuem renda advinda das atividades agrícolas; para os outros $80 \%$, a renda é proveniente de outras atividades. 
Detectou-se que $24,07 \%$ são trabalhadores rurais e que $75,93 \%$ exercem outras atividades. A pesquisa apontou que, além de trabalhadores rurais, existem servidores públicos nas diversas áreas, como educação, saúde e limpeza pública. O comércio local é bastante fraco, empregando apenas os proprietários, e as indústrias próximas exigem mão de obra qualificada.

A renda das famílias residentes nos assentamentos rurais e pequenas propriedades é proveniente da produção agrícola, o que configura apenas renda agrícola. A maioria dedica todo o tempo de trabalho na propriedade, e em nenhuma das famílias detectou-se a pluriatividade.

Em relação à participação dos beneficiários em organizações sociais, $80 \%$ das famílias residentes nos assentamentos rurais e pequenas propriedades participam de pelo menos um grupo. Já nos distritos a situação é bastante diversa, apenas $43 \%$ participam.

Em relação à alimentação, a maioria das famílias dos distritos e dos assentamentos rurais e pequenas propriedades toma café da manhã (81,48\% e 92,5\%, respectivamente), almoçam $(100 \%)$ e jantam $(100 \%)$ nos sete dias da semana. A porcentagem do café da manhã é a menor, pois muitos relataram não estar acostumados a fazer a refeição matinal, principalmente nos dias em que as crianças não têm aulas.

Das famílias que possuem crianças frequentando escolas ou creches, $100 \%$ recebem refeição escolar, em média, uma vez ao dia. Nos distritos, algumas escolas passaram a funcionar em período integral no ano de 2013, e as crianças que estão matriculadas nessas escolas recebem três refeições diárias, assim como nas creches. A merenda escolar é complementar e pode contribuir, mesmo que indiretamente, para a melhora dos níveis de insegurança alimentar, além de ser importante para o orçamento doméstico, gerando menos gastos em casa com alimentação das crianças, de acordo com o IBASE (BRASIL, 2008).

Todas as famílias entrevistadas nos distritos afirmaram efetuar a compra de alimentos em supermercados, assim como as famílias dos assentamentos rurais e pequenas propriedades. Nos distritos, 50,24\% das famílias possuem dívidas com alimentos, contraídas nos supermercados locais, já nos assentamentos rurais e pequenas propriedades, as famílias efetuam suas compras à vista.

Ao serem questionadas sobre o que acontece com a alimentação das crianças menores de 14 anos durante as férias escolares, $63 \%$ das famílias nos distritos disseram que não há alteração; $18,12 \%$ disseram que piora e $18,9 \%$ disseram que melhora. Nos assentamentos rurais e pequenas propriedades, $15,21 \%$ responderam que melhora a alimentação; 77,08\% disseram que não há alteração e 7,71\% não têm filhos menores de 14 anos.

Não foi possível levantar o percentual de famílias que apresentam problema crônico de saúde. De acordo com os agentes de saúde, as doenças mais comuns são hipertensão e/ ou colesterol alto.

Em relação à situação de trabalho dos chefes de família dos distritos, 20,37\% têm trabalho permanente, ou seja, têm registro em carteira ou são servidores públicos efetivos e/ou comissionados; $66,67 \%$ trabalham sem registro em carteira, temporariamente ou por conta própria; $1,85 \%$ são aposentados e $11,11 \%$ estão desempregados ou à procura de emprego. No caso dos chefes de família dos assentamentos rurais e pequenas propriedades, $90 \%$ trabalham somente nos lotes; 2,5\% trabalham como servidor público (auxiliar de serviços gerais na escola); $2,5 \%$ estão procurando emprego e $5 \%$ são trabalhadores rurais com carteira assinada. Todas as mulheres exercem algum tipo de atividade na propriedade em que residem.

\subsubsection{Caracterização da (in) segurança ali- mentar das famílias}

Seguindo o que preconiza a Escala Brasileira de Insegurança Alimentar (EBIA), a pesquisa detectou que $28,72 \%$ das famílias pesquisadas beneficiárias do PBF se encontram em situação de segurança alimentar (SA), ou seja, não apresentam nenhuma restrição alimentar e preocupações futuras com a falta de alimentos.

Já 71,28\% apresentam níveis de insegurança alimentar (IA) ou algum tipo de privação de alimentos. A pesquisa revelou que $54,25 \%$ das famílias apresentam insegurança alimentar leve (IAL), ou seja, as famílias quando há preocupação ou incerteza quanto 
ao acesso aos alimentos. Ainda $12,77 \%$ apresentam insegurança alimentar moderada (IAM), quando há restrições quantitativas especialmente relevantes entre pessoas adultas. Apenas 4,26\% apresentaram insegurança alimentar grave (IAG), caracterizada pela fome entre adultos e/ou crianças.

O nível de segurança alimentar nos distritos $(31,48 \%)$ é maior do que nos assentamentos $(25 \%)$. Em relação à insegurança alimentar, nos assentamentos não aparece a IAG, enquanto que nos distritos o índice desta é de 7,41\%.

O cruzamento das variáveis com os níveis de (in) segurança alimentar permitiu identificar as principais dificuldades das famílias e as oportunidades para alcançar a segurança alimentar. De acordo com a análise feita, as variáveis renda e escolaridade interferem diretamente na segurança alimentar das famílias. Quanto maior a renda, melhores são os níveis de segurança alimentar. A maioria das famílias complementa a renda com o valor do benefício do PBF que, segundo eles, contribui de forma significativa nos gastos com alimentação e, nesses casos, contribuem para o aumento dos níveis de segurança alimentar.

A diversificação da produção das famílias proporciona-lhes estágios mais favoráveis quanto à segurança alimentar. Na pesquisa, famílias nessas condições apresentaram um percentual de $30,43 \%$ em condições de segurança alimentar, com redução nos percentuais de IAM. As famílias com maior diversificação de culturas apresentam $69,57 \%$ de insegurança alimentar, enquanto que as pouco diversificadas apresentam $86,67 \%$. Esse dado vem reforçar as conclusões de estudos (DUVAL; FERRANTE, 2008) que têm mostrado que, nos lotes onde a diversificação agrícola é maior, há melhores condições de se ter uma alimentação saudável.

Ainda que alguns estudos revelem uma tendência à diminuição de níveis mais críticos de insegurança alimentar mediante um maior percentual de autoconsumo, pode-se afirmar que essa tendência não se confirmou na pesquisa realizada, uma vez que muito pouco do que é consumido pelas famílias é produzido por elas. A pesquisa apontou que apenas $25 \%$ das famílias consomem quase tudo do que é produzido na propriedade. E, dentre as que consomem quase tudo vindo da propriedade, 70,59\% estão em condição de insegurança alimentar. A conclusão é de que quanto menor a renda dessas famílias, maior o autoconsumo.

\section{Considerações finais}

O estudo desenvolvido demonstra a importância da discussão da avaliação das políticas sociais direcionadas à segurança alimentar das famílias rurais, em especial o Programa Bolsa Família. Observa-se interesse, por parte do governo e também da população, na avaliação dos programas e das políticas públicas, avaliação esta que reflete maior transparência nas ações governamentais.

Dentre as variáveis pesquisadas, observou-se que os principais entraves para a efetividade social do programa na segurança alimentar das famílias em questão estão relacionados à baixa renda, baixa escolaridade, ausência de atividades pluriativas, dificuldade de acesso ao crédito, falta de qualificação, ausência de assistência técnica e tendência ao trabalho informal, no caso dos distritos. Percebeu-se baixa qualificação das famílias, pouca diversificação da produção e uma grande dificuldade no acesso às políticas públicas.

O universo empírico estudado não completa o ciclo da política com o estágio de avaliação. A avaliação constitui exame sistemático do programa e destaca-se como um instrumento valioso para a gestão. Ela permitiria, no caso específico, a identificação das fragilidades levantadas pela pesquisa, a transparência das ações e correções do programa. Os resultados do programa com as famílias rurais não são monitorados pelo governo e atores sociais.

Em relação à diferença na efetividade do Programa Bolsa Família entre as famílias residentes nos distritos e assentamentos rurais, verificou-se que as famílias residentes nos distritos têm maior facilidade em acessar as ações desenvolvidas pela gestão local, ações essas que geram oportunidades de capacitação, de trabalho e renda. Essas ações são elementos necessários à emancipação dessas famílias e terão reflexo direto nos níveis de segurança alimentar e se traduzirão em maior efetividade do programa nos distritos.

Percebe-se que há muito a evoluir, principalmente no que diz respeito à gestão 
local na articulação com outras secretarias para o acompanhamento do cumprimento das condicionalidades, na identificação das famílias que estão excluídas do Programa e na oferta de capacitação profissional aos beneficiários que vivem no meio rural. Os produtos propostos neste estudo serão caminhos importantes de avaliação continuada e de transferência de conhecimento ao poder público dessa política social tão relevante, especificamente para as famílias rurais.

\section{Referências}

ALMEIDA, L. M. M. C. Estrutura de governança e gestão das redes e programas de segurança alimentar: análise comparativa entre municípios paulistas. 2009. 220p. Relatório técnico-científico (Pós-Doutorado) - Faculdade de Engenharia Agrícola, Universidade Estadual de Campinas, Campinas, SP.

BRASIL. Instituto Brasileiro de Análises Sociais e Econômicas. Repercussões do Programa Bolsa Família na Segurança Alimentar e Nutricional das Famílias Beneficiadas. Documento sintese. 2008. Disponível em: <http:/ / www.ibase.br/pt/wp-content/uploads/2011/06/ segal-repercussões-do-bolsa-família.pdf $>$. Acesso em: 31 jul. 2012.

Instituto Brasileiro de Geografia e Estatística. Segurança alimentar. 2010a. Disponível em: <http:// www.ibge.gov.br/home/estatistica/populacao/seguranca_alimentar_2004_2009/pnadalimentar.pdf >. Acesso em: 31 jul. 2012.

Censo demográfico. 2010b. Disponível em: $<$ http://cidades.ibge.gov.br/xtras/perfil.php?lang= $\&$ codmun $=521880 \&$ search $=$ goias $\mid$ rio-verde. Acesso em: 19 abr. 2014.

Ministério do Desenvolvimento Social e Combate à Fome. Bolsa Família. 2013. Disponível em: <http:/ / www.mds.gov.br/bolsafamilia>. Acesso em: 22 maio 2013.

. Relatório de Informações Bolsa Família e Cadastro Único. 2014a. Disponível em: <http:/ / aplicacoes.mds. gov.br/sagi/RIv3/geral/relatorio.php >. Acesso em: 19 abr. 2014

. A extrema pobreza no seu município. 2014b. Disponível em: <http://aplicacoes.mds.gov.br/ead/ri/ carrega_pdf.php?rel=extrema_pobreza $>$. Acesso em: 19 abr. 2014.

CAMPELLO, Tereza; NERI, Marcelo Côrtes (Org.). Programa Bolsa Família: uma década de inclusão e cidadania. Brasília: IPEA, 2013.

DUVAL, Henrique Carmona; FERRANTE, Vera Lúcia Silveira Botta. Autoconsumo e políticas municipais: perspectivas de segurança alimentar e de desenvol- vimento. In: FERRANTE, Vera Lúcia Silveira Botta; WHITAKER, Dulce Consuelo Andreatta (Org.). Reforma agrária e desenvolvimento: desafios e rumos da política de assentamentos rurais. Brasília: Ministério do Desenvolvimento Agrário, 2008. p. 308-323.

KAGEYAMA, Angela A. Desenvolvimento rural: conceitos e aplicação ao caso brasileiro. Porto Alegre, RS: EDUFRGS, 2008.

MENEZES, Francisco. Panorama atual da segurança alimentar no Brasil. Brasília: IBASE, 1998. Disponível em: <http:/ / amar-bresil.pagesperso-orange.fr/documents/secual/san.html >. Acesso em: 5 nov. 2012.

PAIVA, Luis Henrique; FALCÃO, Tiago; BARTHOLO, Letícia. Do Bolsa Família ao Brasil Sem Miséria: um resumo do percurso brasileiro recente na busca da superação da pobreza extrema. In: CAMPELLO, Tereza; NERI, Marcelo Côrtes (Org.). Programa Bolsa Família: uma década de inclusão e cidadania. Brasília: IPEA, 2013. p. 25-46.

PAULILLO, Luiz. Fernando; PESSANHA, Lavínia. Segurança alimentar, políticas públicas e regionalização: In. PAULILLO, Luiz. Fernando et al. Reestrutração agroindustrial, políticas públicas e segurança alimentar regional. São Carlos: Edufscar, 2002.

PAULILLO, Luiz Fernando; ALVES, Francisco (Org.). Reestruturação agroindustrial: políticas públicas e segurança alimentar regional. São Carlos, SP: EDUFSCAR, 2009.

PAULILLO, L.F. Entraves para políticas de segurança alimentar: uma análise comparativa da eficácia e aplicabilidade dos programas e redes de inclusão criadas em municípios paulistas. Relatório de Projeto apresentado ao Conselho Nacional de Desenvolvimento Científico e Tecnológico - $\mathrm{CNPq}$, Bolsa Produtividade em Pesquisa. São Carlos, 2010.

SANTANA, Jomar Álace. A evolução dos programas de transferência de renda e o Programa Bolsa Família. In: SEMINÁRIO POPULAÇÃO, POBREZA E DESIGUALDADE, 1., 2007, Belo Horizonte, MG. Resumos... Belo Horizonte, MG: Cedeplar/UFMG, 2007. p. 1-19.

SANTOS, Leandro de Lima. Políticas públicas de reforma agrária e segurança alimentar: análise comparativa dos agricultores familiares no território rural Vale do Rio Vermelho - GO. 2011. 123f. Dissertação (Mestrado em Agronegócio)-Escola de Agronomia e Engenharia de Alimentos, Universidade Federal de Goiás, Goiânia, 2011.

TAKAGI, Maya; BELIK, Walter. A implantação da política de segurança alimentar e nutricional no Brasil: entre a caridade e os gastos sociais. In: ORTEGA, Antônio Cesar; ALMEIDA FILHO, Niemeyer (Org.). Desenvolvimento territorial, segurança alimentar e economia solidária. Campinas, SP: Alínea, 2007. p. 187-207.

TRALDI, Daiane Roncato Cardozo. Efetividades e entraves do Programa Bolsa Família no município de Araraquaral SP: um olhar sobre a segurança alimentar e nutricional dos beneficiários. 2011. 192f. Dissertação (Mestrado em Desenvolvimento Regional e Meio Ambiente) - Centro Universitário de Araraquara, Araraquara, 2011. 